\title{
Transfer of calcium -45 and strontium-90 from medium to plant and their translocation in micropropagated potato
}

\author{
N.N. Barthakur, D.J. Donnelly and A. Habib \\ Macdonald Campus, McGill University, Department of Natural Resource Sciences, \\ H9X 3V9 Sainte-Anne-de-Bellevue, Quebec, Canada
}

\begin{abstract}
The uptake and translocation of calcium-45 and strontium-90 were studied in potato (Solamum truberonum) cv. Sierra micropropagated plantiets and $\mathrm{cv}$. Norland microtubers. The absorption of $\mathrm{Ca}-45$ or $\mathrm{Sr}-90$ by plantlets was not significant as the concentrations of either $\mathrm{CaCl}_{2}$ or $\mathrm{SrCl}_{2}$ were increased in the treatment solution. However, the percentage uptake of Ca-45 decreased with increasing concentration of these salts. Uptake by roots, sterns, petioles, and leaves differed significantly $(p<0.05)$ regardless of salt concentration. When shoot-tips were immersed in the treatruant solutions containing various concentrations of these salts for $161 \mathrm{~h}$ while the plantlets were held in a vertically inverted position, considerable amounts of radiolabel were still translocated towards the roots. The $\mathrm{Ca}-45 / \mathrm{Sr}-90$ ratio assumed a wide range of values as equal amounts of each radioisotope were fed either through root-or tip-immersion. A differential uptake and translocation between the isotopes occurred for the plantlets independent of feeding mechanism. A drop of $\mathrm{Ca}-45$ or $\mathrm{Sr}-90(18.5 \mathrm{kBq})$ onto the periderm of microtubers was restricted in movernent to the periderm with virtually no penetration into the imer cortical or medulary tissues. The difficion coefficient of $\mathbf{S r}-90 \mathrm{an}$ the periderm of Noriand microtubers was estimated at $6.5 \times 10^{-8} \mathrm{~cm}^{2} / \mathrm{s}$.
\end{abstract}

\section{INTRODUCTION}

Tissue culture used in combination with the radiotracer techniques provides an ideal system to study transfer of radioisotopes from the culture medium into roots and aerial parts of plants. Micropropagated plantlets grown on defined nutrient medium not only allow the minimum quantity of a radio-labeled nutrient to be applied but the entire plantlet can be harvested, and all of its parts counted, decreasing sampling errors. The system reduces the cost of research without compromising on procedural protocol compared with nutrient transport studies involving field-grown crops. The time to complete a certain number of replications is also greatly reduced when tissue-cultured plantlets are used instead of field-grown crops. Tissue-cultured plantlets are clones that may eliminate much of the biological variability usually encountered in radioactive uptake studies with living organisms. Thus, the present research was undertaken in the hope that such a system could provide new information on the transfer of radioisotopes from the substrate into potato plants and tubers. Potato (Solanum ruberosum) was chosen as a test plant because of its ease of growth in culture, its importance as a major world food crop, and the relatively large surface area its tubers present to a substrate contaminated with radioisotopes.

Calcium (Ca) and strontium ( $\mathrm{Sr}$ ) belong to the second group of elements in the periodic table but the former plays an important role in plant growth and development [1]. Sr-90 has the potential of contaminating foodstuffs via uptake by roots or directly into other plant tissues. This poses a problem because Sr-90 concentrates in bones on ingestion [2-3]. $\mathrm{Ca}-45$ and $\mathrm{Sr}-90$ accumulation in potato tubers have been reported to be diffusion-controlled and are apparently independent of plant root absorption [4]. The literature on the uptake and translocation of $\mathrm{Sr}-90$ by potato plants is rare. The radicecology of $\mathrm{S}_{\mathrm{r}}-90$ has been reviewed by several authors [5-6], and the release, transport, and distribution of $\mathrm{Sr}-90$ after the Chernobyl disaster have been adequately described [7].

The objectives of this study were: (a) to examine the uptake and translocation of $\mathrm{Ca}-45$ and $\mathrm{Sr}-90$ by potato plantlets as a function of the concentration of the chloride salts of each radioisotope in the treament solution; (b) to determine whether differential uptake occurs between these two radioisotopes when plantlet roots and shoot-tips are treated with equal announts of each; (c) to study the movement of applied radioisotopes into microtuber tissues. 


\section{MATERIAIS AND METHOD}

Potato cvs. Norland and Sierra plantlets were micropropagated from 1-cm-long single-node cuttings with one lateral bud and subtending leaf. Culture tubes $(25 \times 150 \mathrm{~mm})$ contained $10 \mathrm{ml}$ of MS basal salt medium prepared according to conventional procedure [8]. Cultures were incubated in a growth chamber at $25^{\circ} \mathrm{C}$ and $40 \mu \mathrm{mol} \mathrm{m} \mathrm{m}^{-2} \mathrm{~s}^{-1}$ photon flux density (cool white fluorescent) with $16 / 8 \mathrm{~h}$ (day/night) cycle. The mean $\pm \mathrm{SD}$ height and fresh weight of 1 -month-old Sierra plantets used in these experiments was $10.7 \pm 0.6 \mathrm{~cm}$ and $3.9 \pm$ $0.4 \mathrm{~g}$, respectively. Microtubers of $\mathrm{cv}$. Norland were induced using layered plantlets in high-sucrose MS medium at $15^{0} \mathrm{C}$ under $40 \mu \mathrm{mol} \mathrm{m} \mathrm{m}^{-2} \mathrm{~s}^{-1}$ photon flux density with $8 / 16 \mathrm{~h}$ cycle [9]. The average size (diameter) and weight of microtubers used in these experiments was $1.5 \mathrm{~cm}$ and $0.7 \mathrm{~g}$, respectively.

Aqueous solutions of $\mathrm{Ca}^{45} \mathrm{Cl}_{2}$ and $\mathrm{Sr}^{\circ} \mathrm{Cl}_{2}(>99 \%$ radiochemical purity) were purchased from Amersham Pharmacia Biotech, Inc., Quebec, Canada, and Isotope Products Laboratory, Bubank, California, respectively. Plantlets or microtubers were transferred to the radioisotope laboratory for the application of Ca-45 and Sr-90. The growth medium was carefully removed from roots using nunning water, and the plantlets were transferred to aqueous solutions of $0,3,9$, or $18 \mathrm{mM} \mathrm{CaCl}_{2}$ or $\mathrm{SrCl}_{2}$ for uptake studies. These were of 42 and $161 \mathrm{~h}$ duration. Some treated plantlets were reserved for autoradiography. Others were divided into roots, stems, petioles and leaves and used for scintillation counting. Root samples were prepared following rinsing of roots 3 times in distilled water to remove loosely bound radionuclides.

The effect of plantlet orientation on uptake and translocation of $\mathrm{Ca}-45$ and $\mathrm{Sr}-90$ was studied by vertically inverting the plantlets while immersing the apex of the topmost true leaf (shoot-tip) into radio-labeled solutions. The semi-solid MS medium was not removed from the roots for this experiment. Following immersion, the soot-tips were carefully removed to avoid cross-contamination and the remaining plant organs were used for autoradiography or scintillation counting.

One drop $(10 \mu \mathrm{l})$ of $\mathrm{Ca}^{45} \mathrm{Cl}_{2}$ or $\mathrm{Sr}^{50} \mathrm{Cl}_{2}(18.5 \mathrm{kBq}$ activity) was applied onto the periderm of 3 intact Norland microtubers. After an interval of $96 \mathrm{~h}$, slices were made starting at $1 \mathrm{~mm}$ from the application site, and these were used for autoradiography or scintillation counting.

Root samples for scintillation counting were shaken vigorously during rinsing for 2-3 min. Tissues were digested in an oven at $60^{\circ} \mathrm{C}$ for $2 \mathrm{~h}$ with $1 \mathrm{ml}$ of $33 \%$ hydrogen peroxide and $66 \%$ perchloric acid $(1: 2 \mathrm{v} / \mathrm{v})$. The samples were counted in a Jiquid scintillation spectrometer (Model LKB 1219 Rackbeta, Wallac, Turku, Finland). Sierra plantlets were also used for autoradiography using $X$-ray films.

Each experiment was replicated 3 to 4 times, and the mean uptake activities ( $t$ standard error of the mean (SE)) were calculated and reported. The data was analyzed using one way ANOVA provided by a statistical sottware package [10].

\section{RESULTS AND DISCUSSION}

The percentage uptake of $\mathrm{Ca}-45$ decreased for all plant parts as the concentration of either $\mathrm{SrCl}_{2}$ or $\mathrm{CaCl}_{2}$ increased in the treatment solution. Since both $\mathrm{Ca}$ and $\mathrm{Sr}$ salts produced similar results, only the effect of one salt is shown (Fig 1a). There was a significant difference $(p<0.05)$ between the Ca-45 activities in roots, stems, petioles, and leaves regardless of salt concentration after $42 \mathrm{~h}$ of exposure. Roots absorbed the greatest amount and the petioles the least $\mathrm{Ca}-45$. In contrast, the root percentage uptake of $\mathrm{Sr}-90$ increased as the treatment solution concentration increased from zero to $3 \mathrm{mM}$ but decreased at higher salt concentrations (Fig. Ib). As seen with $\mathrm{Ca}-45$ uptake, there was a significant $(\mathrm{p}<0.05)$ difference between the Sr-90 activities in plantlet parts; the roots had the greatest and the petioles the least $\mathrm{Sr}-90$. However, $\mathrm{Ca}-45$ or $\mathrm{Sr}-90$ activities in roots, stems, petioles, and leaves were not significantly different whether $\mathrm{SrCl}_{2}$ or $\mathrm{CaCl}_{2}$ concentrations were varied. As substrate concentrations increased, the ratio of $\mathrm{Ca}-45 / \mathrm{Sr}-90$ after $42 \mathrm{~h}$ decreased from $>1.0$ to $<$ 1.0 for all plant parts. The $\mathrm{Ca}-45 / \mathrm{Sr}-90$ ratio in all plant parts was $>1.0$ for root-fed plantlets only in treatment solutions with zero $\mathrm{Ca}$ and $\mathrm{Sr}$ chloride salts. Interestingly, the $\mathrm{Ca}-45 / \mathrm{Sr}-90$ ratio was consistently greater when the $\mathrm{CaCl}_{2}$ concentration was increased compared with increased $\mathrm{SrCl}_{2}$ in the treatment solution (Fig. 2a) although the difference was not significant at $\mathrm{p} \leq 0.05$. The variation in the ratio may indicate that $\mathrm{cv}$. Sierra discriminated in uptake and translocation between $\mathrm{Ca}-45$ and $\mathrm{Sr}-90$. When equal quantity of either labeled $\mathrm{Ca}-45$ or $\mathrm{Sr}-90(18.5 \mathrm{kBq})$ was added to the treatment solution, mixing of each radioisotope with its 
unlabelled species occurred as the concentration of each salt increased. Plantlet uptake of unlabelled Ca correspondingly increased in competition with $\mathrm{Ca}-45$, and the $\mathrm{Ca}-45 / \mathrm{Sr}-90$ ratio decreased to a fraction because of higher uptake of $\mathrm{Sr}-90$ compared with $\mathrm{Ca}-45$ in presence of either salt

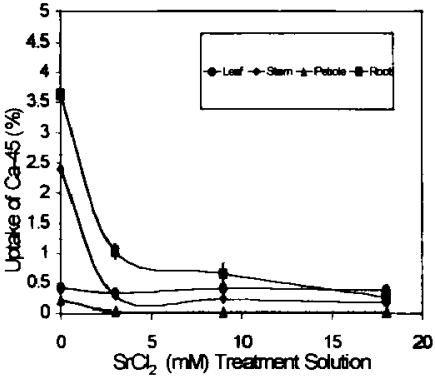

a)

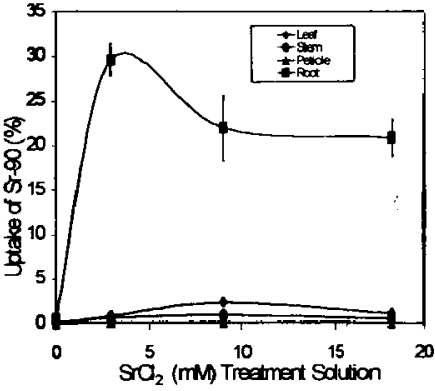

b)

Frgmre 1: Percentage ugtake of a) $\mathrm{Ca}-45$ and b) $\mathrm{Sr}-90$ as a furction of $\mathrm{SrCl}_{2}$ concentration by Sierra plantlets. The error bers indicate $\mathrm{SE}$

Autoradiography supported the counting results; autoradiographs showed higher absorption of $\mathrm{Sr}-90$ compared with $\mathrm{Ca}-45$ as the concentrations of either $\mathrm{CaCl}_{2}$ or $\mathrm{SrCl}_{2}$ was increased

Shoot-tip feeding and plantlet inversion affected the $\mathrm{Ca}-45 / \mathrm{Sr}-90$ ratios. Ratios reached a maximum at 3 $\mathrm{mM}$ for $\mathrm{CaCl}_{2}$ and decreased at higher concentrations for leaves, stems, and roots. Ratios reached a maximum at $18 \mathrm{mM}$ for $\mathrm{SrCl}_{2}$ in all plant parts; > I for leaves and stems, but $<1$ for roots at this concentration (Fig. 2b).

The percentage uptake and translocation of $\mathrm{Ca}-45$ into leaves and stems was significantly lower $(\mathrm{p}<0.05)$ in shoot-tip compared with root-fed plantlets in $\mathrm{SrCl}_{2}$ treatment solutions. The percentage uptake and translocation of $\mathrm{Sr}-90$ into leaves was significantly lower $(\mathrm{p}<0.05)$ in shoot-tip compared with root-fed plantiets in both $\mathrm{CaCl}_{2}$ and $\mathrm{SrCl}_{2}$ treatment solutions.

The autoradiographic images of inverted plantlets showed no $\mathrm{Ca}-45$ uptake and weak Sr-90 activity as the concentration of $\mathrm{CaCl}_{2}$ increased. However, faint images of the plantlets could be seen for $\mathrm{Ca}-45$ activity and strong uptake and translocation of $\mathrm{Sr}-90$ occurred when $\mathrm{SrCl}_{2}$ concentrations of the treatment solutions were increased. The stems showed higher activity levels than other organs. The autoradiograph images supported the counting results. Although activities in the roots were relatively small, considerable translocation occurred from the shoot-tips down towards the roots. $\mathrm{Ca}-45$ and $\mathrm{Sr}-90$ activities were significantly higher $(\mathrm{p}<0.03)$ for rootfed than inverted plantlets in all plant parts in either salt except for $\mathrm{Ca}-45$ activities in leaves and stems in 3 and $9 \mathrm{mM}$ concentrations of $\mathrm{SrCl}_{2}$. This showed that the rate of translocation in root-fed was normally higher than for inverted plantlets.

The percent uptake of $\mathrm{Ca}-45$ by the leaves whose tips were immersed was the highest at zero concentration and decreased markedly as $\mathrm{CaCl}_{2}$ concentration increased in the treatment solutions (Fig. 3a). Similar results were obtained when the concentrations of $\mathrm{SrCl}_{2}$ in the test solutions were increased. The percent uptake of $\mathrm{Sr}-90$ was considerably greater than that of $\mathrm{Ca}-45$ at all $\mathrm{CaCl}_{2}$ (Fig. $3 \mathrm{~b}$ ) and $\mathrm{SrCl}_{2}$ (not shown) concentrations. The $\mathrm{Ca}-45$ transport rate along the periderm was negligible in Norland microtubers. The entire applied activity of Ca-45 was essentially at the site of application after $96 \mathrm{~h}$. The movernent of Sr-90 was greater than that of $\mathrm{Ca}-45$ but still low and localized to the periderm (Fig. 4). Less than $12 \%$ of the applied $\mathrm{Sr}$ 90 activity was detected at $0.1 \mathrm{~cm}$ from the application site and at $0.5 \mathrm{~cm}$ no activity was detected 
There was almost no penetration of $\mathrm{Ca}-45$ or $\mathrm{St}-90$ into the interior cortical tissue of the microtuber. Autoradiographic images confirmed the liquid scintillation counting results for slices of the periderm and cortical tissue as a function of distance from the application site.

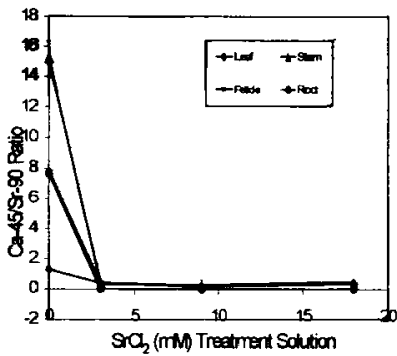

a)

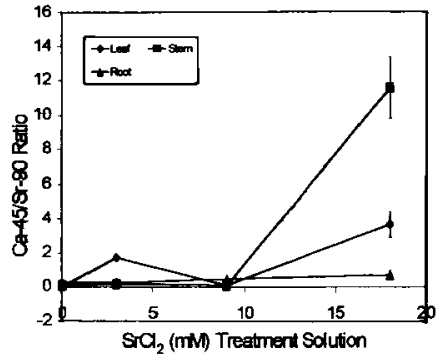

b)

Figare 2: $\mathrm{Ca}-45 / \mathrm{Sr}-90$ ratio versus $\mathrm{SrCl}_{2}$ molsrity a) root-fed and b) inverted and leaf-tip inmersed for Sierra plantlets. The erJor bars indicate $\mathrm{SE}$.

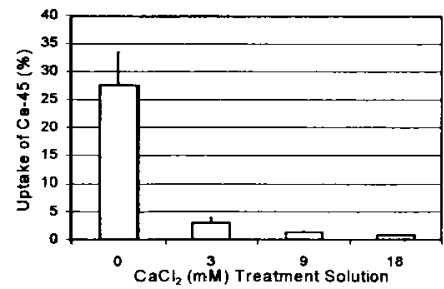

a)

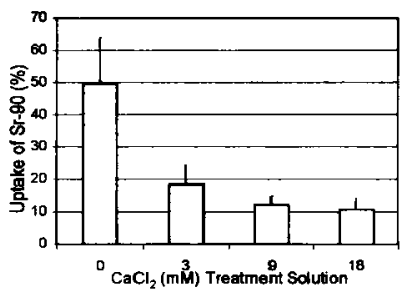

b)

Figere 3: a) $\mathrm{Ca}-45$ and b) $\mathrm{S} r-90$ uptake by non-immersed portion of leaves whose tips were immersed in treatment solutions for Sierra plantlets versus $\mathrm{CaCl}_{2}$ molarity. The error bers indicate $\mathrm{SE}$.

The diffusion coefficient, D, was determined for $\mathrm{Sr}-90$ movement through the periderm and cortical tissue by using the Fick's second law of diffusion as shown in equation (1),

$$
\partial \mathrm{C} / \partial \mathrm{t}=\mathrm{D} \partial^{2} \mathrm{C} / \partial \mathrm{x}^{2}
$$

where $\mathrm{C}=$ the concentration of the diffusing substance, $\mathrm{x}=$ the distance traveled, and $\mathrm{t}=$ the time of diffusion. A solution of equation (1) can be written as [6],

$$
\mathrm{D}=\left(\mathrm{x}_{2}^{2}-\mathrm{x}_{1}^{2}\right) /(4 t) \ln \left(\mathrm{C}_{1} / \mathrm{C}_{2}\right)
$$

where $C_{1}$ and $C_{2}$ were determined at two arbitrary points $x_{1}$ and $x_{2}$, respectively. D was calculated by using 
equation (2), and its average value for $\mathrm{S} \tau-90$ on potato periderm was obtained as $6.5 \times 10^{-8} \mathrm{~cm}^{2} / \mathrm{s}$. For Ca-45 the D-value was much smaller and a high degree of uncertainty was therefore involved in its calculation and has not been quoted here. The diffusion coefficient of Sr-90 for Norland periderm was much lower than those reported for certain soils which varied from $0.6-8.1 \times 10^{-7} \mathrm{~cm}^{2} / \mathrm{s}[6]$.

The periderm is known to act as a protective layer to prevent water loss from the tuber and to impede the microbial infestations by soil pathogens [11]. The periderm is suberized with hydrophobic properties similar

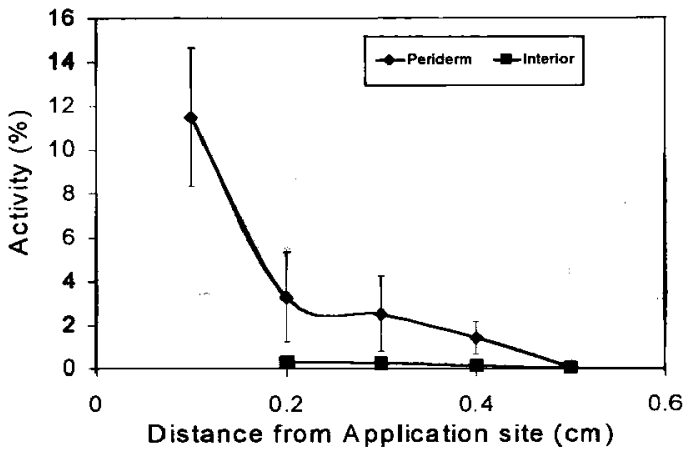

Flgure 4: Migration of Sr-90 on periderm and into potato tuber of cv. Norland. The error bars indicate $\mathrm{SE}$.

to wax. Our calculations indicate a very low value of D for Sr-90 and is consistent with the physical characteristics of the structure of periderm. The periderm (skin) of potato tubers is expected to prevent any significant amount of uptake of $\mathrm{Sr}-90$ or $\mathrm{Ca}-45$ directly via diffusion from contaminated substrates or soil solutions. These results indicate that contaminated potatoes at the level used in these experiments can be used as animal feed or even food if they are peeled since negligible amounts of these radioisotopes are transferred into the inner tissues of potato.

\section{CONCLUSIONS}

The uptake and translocation of $\mathrm{Ca}-45$ and $\mathrm{Sr}-90 \mathrm{by} \mathrm{cv}$. Sierra potato plantlets were significantly $(p<0.05)$ different in different plant organs irrespective of the concentrations of $\mathrm{CaCl}_{2}$ or $\mathrm{SrCl}_{2}$ in the treatment solutions. The $\mathrm{Ca}-45 / \mathrm{Sr}-90$ ratio suggested that $\mathrm{cv}$. Sierra may discriminate between the uptake of radiocalcium and radiostrontium. The vertically inverted plantlets absorbed and translocated considerable amounts of $\mathrm{Ca}-45$ and $\mathrm{Sr}-90$. The movement of $\mathrm{Ca}-45$ in the periderm was negligible and $\mathrm{Sr}-90$ was extremely slow when applied to the periderm with no appreciable penetration into the cortical tissue. The autoradiographic imagings supported the counting results. Thus, potatoes may be peeled before their use as food or feed if the substrate is lightly contaminated by radioactive fallout or accident.

\section{Acknowledgments}

The authors acknowledge the Natural Sciences and Engineering Research Council (NSERC) of Canada for a research grant (OGP0010245) that supported the present project. 


\section{References}

[1] Palta, P, J. HortScience, 31 (1996) 51-57.

[2] Nielsen, O.J. A literature review on radioactivity transfer to plants and soil, Riso Report-450, Riso National Laboratory, DK-4000, Roskilde, Denmark, 1981, pp. 78.

[3] Yera, S.T., Vallejo, V.R, Valcke, E., Colle, C, Forstel, H., Millan, R. and Jouglet, H. J. Environ. Radioactivity, 45 (1999) 191-217.

[4] Melnikova, MK and Baranova, Z.A. On the mechanism of Ca and Sr uptake (on the example of radiocalcium and radiostrontium) by potato tubers, Radiological Concentration Processes, Proceedings of an Intemational Symposium, Stockholm, April 1966, B. Aberg and B.P. Hungate Eds. (Pergamon Press, New York, 1966) pp. 1040.

[5] Kulikov, V.N and Molchanova, V.I. Continentel Radioecology, Soil and Freshwater Ecosystems, (Plenum Press, Nauka Publishers, Moscow, 1982) pp.174.

[6] Klechkovskii, M.V., Polikarpov, G.G and Aleksakhin, M.R. Eds. Radioecology (John Wiley \& Sons, New York,1973, A Halsted Press Book, Israel Program for Scientific Translations) pp.370. Transiated from Russian by Kaner, N., Mills, $\mathbf{H}$ and translation edited by Greenberg, D.

[7] Wamer F. and Harrison, M.R. Eds. Radioecology after Chemobyl, Biogeochemical Pathways of Artificial Radionuclides, (John Wiley \& Sons, New York, 1993) pp. 367.

[8] Murashige, T. and Skoog F. Physiologia Plantanum, 15 (1962) 473-497.

[9] Leclerc, Y., Donnelly, D. J. and Seabrook, J.E. A. Plant Cell Tiss. Org. Cult 37 (1994) 113-120.

[10] SigmaStat, Jandel Scientific MmbH, Schimmelbuschstrasse 25, 40699 Erkrath, Germany,

[11] Peterson, R.L., Barker, W.G, and Howarth, J. M. Development and structure of tubers, Potato Physiology (Academic Press, Inc. New York, 1985) pp. 123-147. 